$\underline{\text { Submitted to Journal of Materials Science (October 2016) }}$

\title{
Effect of severe plastic deformation on the biocompatibility and corrosion
}

\section{rate of pure magnesium}

\author{
Cláudio L. P. Silva ${ }^{1}$, Ana Celeste Oliveira ${ }^{1}$, Cíntia G. F. Costa ${ }^{2}$, \\ Roberto B. Figueiredo ${ }^{3,}$, Maria de Fátima Leite ${ }^{4}$, Marivalda M. Pereira ${ }^{1}$, \\ Vanessa F. C. Lins ${ }^{2}$, Terence G. Langdon ${ }^{5,6}$
}

${ }^{1}$ Department of Metallurgical and Materials Engineering, Universidade Federal de Minas Gerais, Belo Horizonte 31270-901 MG, Brazil

${ }^{2}$ Department of Chemical Engineering, Universidade Federal de Minas Gerais, Belo

Horizonte 31270-901 MG, Brazil

${ }^{3}$ Department of Materials Engineering and Civil Construction, Universidade Federal de Minas Gerais, Belo Horizonte 31270-901 MG, Brazil

${ }^{4}$ Department of Physiology and Biophysics, Universidade Federal de Minas Gerais, Belo Horizonte 31270-901 MG, Brazil

${ }^{5}$ Materials Research Group, Faculty of Engineering and the Environment, University of Southampton, Southampton SO17 1BJ, U.K.

${ }^{6}$ Departments of Aerospace \& Mechanical Engineering and Materials Science, University of Southern California, Los Angeles, CA 90089-1453, U.S.A.

\begin{abstract}
:
It is well established that magnesium has a considerable potential for use as a biodegradable material. This report describes the effect of processing by severe plastic deformation (SPD) on the grain refinement, mechanical behavior, biocompatibility and corrosion behavior of commercial purity $(\mathrm{CP})$ magnesium. The material was received as cast slabs and processed by rolling, equal-channel angular pressing and high-pressure torsion to produce samples with average grain sizes in the range of $\sim 0.5-300 \mu \mathrm{m}$. The results show that severe plastic deformation does not affect the biocompatibility. However, the corrosion behavior is affected by the processing route. Specifically, SPD processing leads to general corrosion as opposed to localized corrosion in the as-cast and hot-rolled condition.
\end{abstract}

Keywords: biocompatibility; corrosion; equal-channel angular pressing; high-pressure torsion; magnesium *Corresponding author: figueiredo@demc.ufmg.br 


\section{Introduction}

Magnesium and its alloys are attracting significant attention among potential biomaterials due to their good mechanical, biological and electrochemical behavior $[1,2]$. Experiments show that magnesium alloys can degrade in vivo and exhibit a good biological response [1,3]. However, the high corrosion rate of this metal in a physiological environment may lead to the premature failure of implants. Also the high rate of hydrogen formation, which is a byproduct of the corrosion of magnesium, may produce an accumulation of this gas around the implant and trigger adverse physiological reactions [4]. Alloying is used to reduce the corrosion rate of magnesium but this procedure may lead to undesirable effects in the biocompatibility depending on the type and amount of alloying elements [1]. The high corrosion rate of magnesium can lead also to a fast delivery of alloying elements and even common elements such as $\mathrm{Zn}, \mathrm{Ca}$ and $\mathrm{Mn}$ can become toxic $[5]$.

Another strategy to control the corrosion rate of magnesium and its alloys is through the use of thermo-mechanical processing since changes in the microstructure affect the corrosion behavior. For example, it has been reported that texture may affect the corrosion rate. Thus, samples cut parallel to the extrusion direction exhibit lower corrosion rates than samples cut perpendicular [6] and it was reported also that the corrosion rate decreases with an increase in the intensity of basal planes parallel to the surface [7]. Decreasing the grain size $[8,9]$ and homogenizing the second phase particle distribution [10] also reduces the corrosion rate. Among the thermo-mechanical processing techniques, severe plastic deformation (SPD) processes [11] are gaining significant attention because of their potential for producing fully-dense bulk samples with exceptionally small grain sizes. Also, 
processing by SPD can improve the homogeneity of the distribution of impurities and second phase particles.

The most attractive SPD techniques are equal-channel angular pressing (ECAP) [12] and high-pressure torsion (HPT) [13]. The former can produce samples with larger dimensions but the low ductility of magnesium prevents ECAP processing at low temperatures. As a consequence, processing of magnesium is usually carried out at high temperatures and the final grain sizes are in the range of a few micrometers [14-17]. By contrast, high hydrostatic pressures are generated during HPT and this permits the processing of materials with low ductility including magnesium [18]. As a consequence, the final grain sizes after HPT are generally smaller than after other thermo-mechanical processing techniques $[19,20]$ and there is also a higher fraction of grain boundaries having high angles of misorientation [21].

Many reports have shown that SPD significantly modifies the properties of magnesium and its alloys. For example, ECAP introduces exceptional superplastic properties at high temperatures [22] and increases the hardness at low temperatures [23]. These improved mechanical properties are attractive for biomedical applications. Thus, a recent report demonstrated the fabrication of a biodegradable stent from a magnesium alloy processed by ECAP followed by extrusion and laser cutting [24]. In addition, HPT processing also shows the development of superplasticity and improved hardness in magnesium alloys and a recent report described the development of exceptional ductility in pure magnesium at room temperature after processing by HPT [25].

Although it is known that SPD improves the mechanical behavior of magnesium and its alloys, its effect on the corrosion behavior is not yet clearly defined because reports have demonstrated different trends. For example, a weaker corrosion resistance, more and 
deeper corrosion pits and a higher rate of mass loss in a 3.5 wt.\% $\mathrm{NaCl}$ solution was reported in pure magnesium after processing by ECAP compared to the as-cast material [26]. On the other hand, a reduced degradation rate in Hank's solution was reported in a magnesium AZ31alloy processed by ECAP by comparison with the squeeze-cast counterpart [27]. An improved corrosion resistance in an AZ31 alloy after processing by ECAP was also reported in $\mathrm{NaCl}$ and phosphate-buffer solution-PBS and this was attributed to the early formation of a protective layer of corrosion products [28]. It was also reported that HPT processing improved the corrosion resistance of a Mg-2 wt.\% Zn-0.24 wt.\% $\mathrm{Ca}$ alloy [10]. A recent report [29] showed that grain refinement can lead to a higher

corrosion rate in materials in which the corrosion current is high, $>10^{-5} \mathrm{~A} . \mathrm{cm}^{2}$, but the presence of grain boundaries may help in developing a passive layer in materials with a low corrosion current, $<10^{-5} \mathrm{~A} . \mathrm{cm}^{2}$, and this suggests that grain refinement may improve the corrosion resistance. Accordingly, the present investigation was initiated to determine the effect of different thermo-mechanical processing operations, including SPD techniques, on the mechanical behavior, biocompatibility and corrosion behavior of pure magnesium.

\section{Experimental material and procedures}

Commercial purity (CP) magnesium (99.7\% purity) was provided by RIMA (Bocaiúva-MG) in the form of as-cast slabs. Plate samples of $5 \mathrm{~mm}$ thickness were cut, heated to $673 \mathrm{~K}$ and subjected to 7 passes of rolling. These sheets were re-heated to $673 \mathrm{~K}$ between each pass and the reduction per pass was $\sim 20 \%$ leading to a final sheet thickness of $\sim 1.0 \mathrm{~mm}$. Some hot-rolled samples were annealed for $1 \mathrm{~h}$ at $523 \mathrm{~K}$ and others were cut into $60 \times 10 \times 1 \mathrm{~mm}^{3}$ sheets which were stacked and wrapped in copper foil for processing by ECAP. The ECAP die had a channel angle of $135^{\circ}$, a $10 \times 10 \mathrm{~mm}^{2}$ square cross-section and electric resistances for heating. This channel angle imposes a strain on the billet of $\sim 0.5$ 
in each pass through the die [30]. The samples were processed by 4 passes at $473 \mathrm{~K}$ using route $\mathrm{C}$ in which the billets are rotated by $180^{\circ}$ between passes [31]. Discs of $10 \mathrm{~mm}$ diameter and $0.8 \mathrm{~mm}$ thickness were cut from the as-cast material and processed by HPT under a pressure of $6.0 \mathrm{GPa}$ up to 10 turns.

The microstructures of the as-cast material and the material processed by hot-rolling and hot-rolling followed by annealing were investigated by optical microscopy after conventional metallographic sample preparation. The samples were cut, embedded in resin, ground and polished to mirror-like finishes and then etched in a $0.05 \%$ nitric acid solution in ethanol to reveal the grain boundaries. Samples of the material processed by hot-rolling followed by ECAP were prepared following a similar procedure but the microstructure was investigated by scanning electron microscopy (SEM) in order to obtain a higher magnification and permit observations of the smaller grains. The ultrafine-grained (UFG) microstructure of the material processed by HPT was examined by transmission electron microscopy (TEM) in which discs of $3 \mathrm{~mm}$ diameter were cut from the HPT-processed samples, ground to thicknesses of $\sim 0.1 \mathrm{~mm}$ and then polished to perforation using a double jet electro-chemical polisher.

Tensile tests were carried out at room temperature using dog-bone specimens with an initial strain rate of $10^{-3} \mathrm{~s}^{-1}$. An electronic extensometer was used to record strain data for all samples except for the material processed by HPT due to the reduced size of the tensile specimens.

In this work, a human osteosarcoma cell line (SAOS-2), obtained from Rio de Janeiro Cell Bank (BCRJ, Brazil), was used to assess the cytotoxicity of Mg-based materials. Firstly, the mitochondrial metabolic activity was quantitatively determined using 3-(4,5-dimethylthiazolyl-2)-2,5-diphenyltetrazolium bromide (MTT) (Sigma-Aldrich, St. 
Louis, MO, USA). This test consisted of the reduction of MTT to an insoluble purple formazan by cleavage of the tetrazolium ring by dehydrogenase enzymes, expressing cell functionality. Secondly, vital status and cell morphology were qualitatively evaluated using a LIVE/DEAD® Viability/Cytotoxicity Kit (Molecular Probes, Eugene, OR, USA). This assay is based on plasma membrane integrity and esterase activity, indicating cell viability. Dulbecco's modified Eagle's medium (DMEM) was used as negative control with 1\% Triton-X 100 (Sigma-Aldrich, St. Louis, MO, USA) as positive control. CP magnesium samples with $48 \mathrm{~mm}^{2}$ area, processed by five different methods (as-cast, hot-rolled, hotrolled + annealing, hot-rolled + ECAP and HPT), were rinsed in $70 \%$ ethanol for 5 min, washed three times in distilled water, dried and sterilized by ultraviolet radiation.

To perform the MTT assay, $3 \times 10^{4}$ cells $/ \mathrm{mL}$ were seeded per well in a 24 -well plate with DMEM containing 10\% fetal bovine serum (FBS), 1\% antibiotic-antimycotic and maintained for $24 \mathrm{~h}$ in a controlled $5 \% \mathrm{CO}_{2} 95 \%$ humidified incubator at $37^{\circ} \mathrm{C}$. After $24 \mathrm{~h}$ of cell culture, cells were directly exposed to materials for $24 \mathrm{~h}$. After the exposure period, materials were removed and $210 \mu \mathrm{L}$ of fresh medium was added in each well. Then, $170 \mu \mathrm{L}$ of MTT solution ( $5 \mathrm{mg} \mathrm{mL}^{-1}$ ) was added and the cells were incubated for $4 \mathrm{~h}$. Afterwards, $170 \mu \mathrm{L}$ of SDS solution $/ 4 \% \mathrm{HCl}$ was placed and incubated for $12 \mathrm{~h}$. Absorbance was quantified at $595 \mathrm{~nm}$ in a spectrophotometer. For each experimental condition, three different measures were taken. All values were normalized to the controls and expressed as a percentage of the cell function. Negative control (functional cells) was considered as $100 \%$. The statistical analysis performed was one way/ANOVA/Bonferroni (GraphPad Prism software, San Diego, CA, USA) and significant differences were considered for $\mathrm{p}<0.05$. 
Significantly, $6 \times 10^{4}$ SAOS cells were seeded on glass coverslips in 6-well plates with $2 \mathrm{~mL}$ of DMEM containing 10\% FBS and 1\% antibiotic-antimycotic, maintained for $24 \mathrm{~h}$ in a controlled $5 \% \mathrm{CO}_{2} 95 \%$ humidified incubator at $37^{\circ} \mathrm{C}$, and then exposed to materials for $24 \mathrm{~h}$. After exposure, the materials were removed, the cells were rinsed twice with phosphate-buffered saline (PBS) and their vital status was observed using the LIVE/DEAD® kit according to the manufacturer's protocol. Cells were examined under a fluorescent confocal microscope (Zeiss LSM 510, Thornwood, NY) with an excitation at $488 \mathrm{~nm}$ and observations at $505 \mathrm{~nm}$ to detect calcein, and excitation at $555 \mathrm{~nm}$ and observations at $605 \mathrm{~nm}$ to detect ethidium homodimer 1.

Electrochemical corrosion tests were carried out using a Princeton Applied Research potentiostat model Versat 3 with 3 electrodes: $\mathrm{Ag} / \mathrm{AgCl}$ as a reference, platinum as counter-electrode and the magnesium samples as the work electrode. The corrosion solution was $\mathrm{NaCl} 3.5$ wt.\%. The scan rate for the polarization tests was $5 \mathrm{mV} / \mathrm{s}$, the frequency range was $10 \mathrm{mHz}$ to $10 \mathrm{kHz}$ and the amplitude was $10 \mathrm{mV}$ in relation to the open circuit potential in the electrochemical impedance spectroscopy tests. The $\mathrm{NaCl}$ solution was used to provide the opportunity to compare the results with published data since this is the most common corrosion environment for testing pure magnesium.

The rate of mass loss was determined in $3.5 \mathrm{wt} . \% \mathrm{NaCl}$ solution using the rate of $\mathrm{H}_{2}$ formation following a procedure described elsewhere [32]. The samples for these tests were ground to \#4000 SiC paper and immersed in the solution. A funnel was used to collect $\mathrm{H}_{2}$ and the volume of gas was tracked up to $6 \mathrm{~h}$ for all conditions of processing. The as-cast material and the materials processed by ECAP and HPT were subjected to longer testing of up to $48 \mathrm{~h}$. 


\section{Experimental results}

Representative images of the microstructures of the magnesium after different processing routes are shown in Fig. 1. It is apparent that the material has a coarse grain structure in the as-cast condition. Hot-rolling promotes significant grain refinement but the grain structure becomes heterogeneous so that there are bands of finer grains $(<10 \mu \mathrm{m})$ intermixed with larger grains in the range of tens of microns, thereby suggesting the occurrence of concentrations of deformation. Annealing at $523 \mathrm{~K}$ for $1 \mathrm{~h}$ after hot-rolling promotes homogenization of the grain size distribution without any significant grain growth whereas processing by ECAP after hot-rolling leads to excellent grain refinement throughout the sample volume. An ultrafine grain structure was also observed after HPT processing. Measurements showed that the average grain sizes were $\sim 480 \mu \mathrm{m}$ in the as-cast condition, $\sim 16 \mu \mathrm{m}$ after hot-rolling, $\sim 24 \mu \mathrm{m}$ after hot-rolling and annealing, $\sim 3.2 \mu \mathrm{m}$ after hot-rolling and ECAP and $\sim 0.56 \mu \mathrm{m}$ after HPT.

The engineering stress vs. strain curves obtained from tensile testing are shown in Fig. 2 for all five experimental conditions. The as-cast material exhibited low strength and low ductility with a yield stress of $\sim 34 \mathrm{MPa}$ and an elongation of $\sim 5 \%$. Hot rolling increased the yield stress to $\sim 110 \mathrm{MPa}$ but with no overall improvement in the ductility. The material subjected to annealing after hot-rolling also exhibited a yield stress of $\sim 110$ MPa but the final elongation increased slightly to $\sim 7 \%$ and the material processed by ECAP after hot rolling exhibited the highest yield stress of $\sim 140 \mathrm{MPa}$ and displayed a reasonable elongation of $\sim 8 \%$. By contrast, the stress-strain curve after HPT exhibited a different behavior with a relatively low strength, a yield stress of $\sim 80 \mathrm{MPa}$, but with an exceptional ductility to an elongation of $\sim 130 \%$. 
The cytotoxicity evaluation using MTT and LIVE/DEAD assays demonstrated that magnesium with different processing histories (as-cast, rolling, rolling and annealing, rolling and ECAP, HPT) generated a non-cytotoxic environment. As shown in Fig. 3, the cytotoxic analyses determined quantitatively by the MTT test demonstrated that SAOS cells exposed to magnesium samples for $24 \mathrm{~h}$ presented no significant alterations in their mitochondrial metabolic activity when compared to the control group $(\mathrm{p}<0.05)$, thereby indicating high levels of cell viability. The experimental groups produced levels of cell function above $50 \%$.

The cytotoxicity analysis using the LIVE/DEAD assay revealed qualitatively that the cells exposed to $\mathrm{Mg}$-based materials for $24 \mathrm{~h}$ maintained suitable cell viability. Figure 4 shows live cells stained with green fluorescence and dead cells stained with red fluorescence. Live cells were clearly observed in all groups, indicating that the LIVE/DEAD results are consistent with the MTT findings. Additionally, the live cells exhibited cell morphologies similar to the control cells with typical cell spreading.

Figure 5 shows the potentiodynamic polarization curves for the samples with different processing histories. It is observed that the as-cast material exhibits a higher open circuit potential and lower corrosion current density which suggests a higher resistance against corrosion. The materials processed by hot-rolling and hot-rolling followed by annealing exhibit a lower open circuit potential and the highest corrosion current density which suggests a lower resistance against corrosion in an aqueous solution of $\mathrm{NaCl} 3.5$ wt.\%. It is also apparent that the material processed by SPD exhibits better corrosion resistance than after hot-rolling. The polarization curves of the material processed by hotrolling and ECAP exhibit an open circuit potential which is almost as high as the as-cast material and the corrosion current density is higher than the current of the as-cast material 
but significantly lower than the hot-rolled condition. The polarization curve of the material processed by HPT is similar to the curve of the as-cast material, thereby suggesting this provides the best corrosion resistance.

The Nyquist diagrams for the different samples are shown in Fig. 6 where $Z_{\text {im }}$ and $\mathrm{Z}_{\mathrm{re}}$ represent the imaginary and the real impedances, respectively. All samples exhibited a capacitive arc suggesting metal dissolution but the diameter of the arc, which directly denotes the resistance to corrosion, differs significantly depending upon the processing history. The diameter of the arc of the samples processed by hot-rolling with and without annealing are smaller than for the as-cast material suggesting they have a poorer corrosion resistance. The lowest corrosion resistance was observed for the hot-rolled condition where the microstructure was more heterogeneous and with a greater deformation concentration than in the hot-rolled and annealed condition. It is reasonable to assume that the heterogeneous microstructure of the hot-rolled condition generates potential gradients which serve to accelerate the metal corrosion and this is in agreement with the polarization curves. However, the samples processed by SPD exhibit higher polarization resistance compared to the as-cast material indicating a higher corrosion resistance. The largest diameter is observed in the material processed by HPT and all curves, except for the HPT material, exhibit an inductive arc in addition to a capacitive arc. It is known that this inductive behavior is associated with the adsorbed species or with pit formation during corrosion $[33,34]$.

The mass loss rate is documented in Fig. 7 for all samples up to immersion times of $6 \mathrm{~h}$ and for the as-cast material and the material processed by SPD up to $48 \mathrm{~h}$. Thus, a lower mass loss rate is observed in the material processed by hot-rolling and annealing. The ascast material exhibits the second lowest rate while the hot-rolled material and the material 
processed by hot-rolling and ECAP exhibit larger rates. The largest rate of mass loss is observed in the material processed by HPT in the first $6 \mathrm{~h}$. This is in disagreement with the results reported by the potentiodynamic polarization curves and the Nyquist diagrams where the HPT-processed material exhibits higher corrosion resistance. Nevertheless, long exposure for more than $6 \mathrm{~h}$ led to a significant decrease in the mass loss rate of the material processed by HPT and ultimately this became the condition having the lowest mass loss rate.

Table 1 shows a summary of the grain size, $d$, the electrochemical potential and current, and the estimated mass loss rate based on the electrochemical experiments using an average hydrogen evolution rate for the first $6 \mathrm{~h}$ of immersion. The yield stress, $\sigma_{\mathrm{y}}$, and elongation to failure, $\Delta \mathrm{L} / \mathrm{L}_{0} \%$, are also shown in Table 1 . It is noted that there is a significant difference between the values of the estimated mass loss rates using the electrochemical tests and the hydrogen evolution tests. This difference was also reported in earlier experiments and it was shown that the best agreement with the mass loss rate measured by the variation of mass of the sample was obtained by hydrogen evolution $[32,35]$. It is worth noting that the HPT-processed material exhibited a corrosion current $<10^{-5}$ A.cm ${ }^{2}$ and therefore the refinement in grain size is expected to lower the corrosion rate [29]. This is in very good agreement with the decrease in corrosion rate observed after $48 \mathrm{~h}$ of immersion as shown in Fig. 7.

It is important to note that there was a change in the overall macroscopic corrosion behavior with the processing conditions. It was noted that localized corrosion occurred in the as-cast material and in the material processed by hot-rolling while there was a more generalized corrosion in the material processed by SPD. The appearances of the corroded 
surfaces of samples of the as-cast material and the material processed by HPT are shown in Fig. 8 for several different exposure periods up to a maximum of $48 \mathrm{~h}$. It is observed that only a fraction of the surface of the as-cast material shows evidence of corrosion after $6 \mathrm{~h}$ of immersion whereas the whole surface of the HPT-processed material shows this evidence. This is in agreement with the higher corrosion rate observed in the HPTprocessed material in the earliest stages of immersion. A longer immersion period led to the formation of a thick layer of corrosion product in the area of localized corrosion in the ascast material. By contrast the material processed by HPT exhibited only a thin layer of corrosion products throughout the sample surface even after $48 \mathrm{~h}$ of immersion.

\section{Discussion}

The results obtained in this investigation show that the mechanical properties and the corrosion behavior of pure magnesium are significantly affected by the thermomechanical processing. A control of these properties, allied to the good biocompatibility, provides an opportunity to use pure magnesium as biodegradable implants with superior performance. It is apparent that the best combinations of properties are attained through processing by SPD.

\section{Mechanical properties}

Pure magnesium usually exhibits poor mechanical properties. Specifically, this material exhibits a low yield stress and low ductility in the coarse-grained condition. Conventional thermo-mechanical processing by hot-rolling improves the strength but does not improve the ductility. However, a moderate ductility is required in many applications. For example, coronary stents are plastically deformed in situ and may withstand more plastic deformation during their lifetime. Therefore the material used in their fabrication must display a reasonable ductility [36]. Also, strength is required for bio-implants with 
structural functions and this becomes even more important for biodegradable implants since the load-bearing area of the product decreases with time. The present results show that ECAP processing leads to the highest yield stress and also displays a good elongation. The improved strength is attributed to the grain refinement while the good elongation is attributed to texture effects. Earlier reports showed that the processing of magnesium alloys by ECAP can lead to a preferential orientation of grains with the basal planes favorably aligned for tensile deformation [37,38]. Thus, the present results demonstrate improvements in both strength and ductility in the material processed by ECAP compared to the as-cast and the hot-rolled conditions.

The mechanical properties of the HPT-processed material exhibits an unexpected low strength compared to the coarser-grained counterparts and an exceptionally high elongation for magnesium at room temperature. The decrease in yield strength of magnesium at very fine grain sizes was reported earlier $[39,40]$ and it was attributed to the onset of grain boundary sliding as a deformation mechanism. Recent reports have shown that fine-grained magnesium can exhibit improved ductility [15] and this is due to a combination of grain boundary sliding and basal slip propagation through grain boundaries having low misorientations [25]. Therefore, HPT processing may be used to produce ductile magnesium with moderate strength. It is worth noting also that the strength of the HPT-processed material is strongly dependent on the strain rate and it may be increased by an appropriate annealing treatment [25].

\section{Cytocompatibility}

A previous report documented good cytocompatibility of the elluates of magnesium alloys WE43, WZ21 and ZW21 dissolved in various physiological media. Also, in vivo experiments showed that implants from these alloys degrade and lead to the formation of 
gas bubbles but this does not compromise the physiological functionality of the tissue [1]. Similarly, a degradation of implants made of magnesium alloys AZ31, AZ91, WE43 and LAE442 and gas bubble formation was reported previously [3]. The metallic implants were compared to a biodegradable polymer and the results suggested an osteoblastic response with increased bone mass surrounding the magnesium implants [3]. These reports demonstrate that alloying magnesium with $\mathrm{Al}$ and rare earth elements does not compromise the biocompatibility of the material. Also, earlier work demonstrated that changes in the texture of extruded rods of pure magnesium induced no cytotoxicity on a mouse osteoblast cell line by using indirect methods [6]. Additionally, cytotoxicity tests of magnesium-based alloys (Mg-2Ag and $\mathrm{Mg}-10 \mathrm{Gd}$ ) and pure magnesium, used as extruded materials, showed that human osteoblasts were mostly alive by LIVE/DEAD staining after 4 or 14 days of exposure and pure magnesium showed moderate cell damage compared with two other alloys studied using these tests [41].

For medical applications, it is extremely important to determine whether the cell behavior is affected by the biomaterials. In this work, a direct contact method was used and both cytotoxic tests MTT and LIVE/DEAD showed clearly that pure magnesium caused no cytotoxic effects on cells. Furthermore, the present results confirm this same result for all processing conditions including when using SPD.

\section{Corrosion behavior}

It is apparent that, in addition to the improved mechanical properties, SPD processing improves the corrosion behavior. The electrochemical tests show that the materials processed by ECAP or HPT exhibit higher corrosion potentials compared to their hot-rolled counterpart and a higher impedance compared to the as-cast and the hot-rolled 
material in an aqueous solution of $\mathrm{NaCl} 3.5 \mathrm{wt} . \%$. These results suggest a higher resistance against pitting in the SPD materials.

In practice, however, the most important observation is the change in the macroscopic corrosion behavior. Magnesium exhibits localized corrosion in the as-cast condition but HPT processing produces a homogeneous corrosion surface. This is in agreement with the Nyquist diagrams in which the HPT-processed material exhibited the highest polarization resistance without an inductive arc. This result is attributed to the pronounced grain refinement that appears to stimulate the formation of a denser protective layer of corrosion product. It is worth noting also that a decrease in the corrosion rate and an increase in the polarization resistance was observed in an Mg-Y-RE alloy and this was attributed to the grain refinement produced by friction stir processing [8].

An early report described a poorer corrosion resistance in pure magnesium processed by ECAP compared to a squeeze-cast condition [26]. The apparent disagreement with the present results is probably due to the processing conditions and final microstructure. Thus, ECAP processing at $573 \mathrm{~K}$ from the cast condition was not effective in refining the grain structure so that grain sizes in the range of $\sim 100-200 \mu \mathrm{m}$ were produced by ECAP [26]. By contrast, in the present experiments the magnesium was first processed by hot-rolling to achieve a partially-refined microstructure and then processed by ECAP to further refine the grain size. It is known that billet failure during ECAP and the final microstructure depends on the initial grain structure [42]. In practice the initial processing by hot-rolling allows a decrease in the ECAP processing temperature of magnesium without billet failure and this prevents grain growth and thus leads to a finer microstructure. Furthermore, the grain size of $\sim 3.2 \mu \mathrm{m}$ for the ECAP-processed material in 
the present experiments was almost two orders of magnitude lower than in the material processed from the cast condition [26] and this changed the corrosion behavior.

A decrease in the corrosion current rate in the $\mathrm{NaCl}$ solution with decreasing grain size was reported earlier [14] for magnesium processed by ECAP. In that work, the ECAP processing was carried out with a back-pressure to prevent billet failure and the final grain size was $\sim 2.6 \mu \mathrm{m}$. The resistance against corrosion with decreasing grain size was attributed to the increase in grain boundaries with high angles of misorientation that promote a more coherent oxide layer [14]. This hypothesis is in agreement with the reduction in corrosion rate observed in the present experiments in the samples with very fine grain sizes.

\section{Summary and conclusions}

1. Samples of CP magnesium in the as-cast condition and processed by hot-rolling, hot-rolling and annealing, hot-rolling and ECAP and HPT were used to evaluate the effect of processing on the mechanical behavior, the citotoxicity and the corrosion behavior in $\mathrm{NaCl}$ solution.

2. Processing by SPD improves the mechanical properties of magnesium. A higher yield strength and ductility were attained by ECAP compared to the as-cast material and the material processed by hot-rolling. Exceptional ductility and moderate strength were achieved by HPT processing. The biocompatibility was not affected either by the processing history or by the grain size of the magnesium.

3. The corrosion rate was strongly affected by the processing history. A lower corrosion potential and reduced polarization resistance were observed after hot-rolling and after hot-rolling and annealing compared to the as-cast material. Material processed by ECAP or HPT exhibited similar corrosion potentials to the as-cast material and the largest 
polarization resistance. All materials exhibited an inductive arc except after HPT processing which was associated with the development of more uniform corrosion.

4. The material processed by HPT exhibits the formation of an homogeneous layer of corrosion product that protects the material and decreases the mass loss rate after long immersion times.

\section{Acknowledgements}

The authors acknowledge Prof. A.M. Goes of the Department of Immunology and Biochemistry (UFMG) for providing the human osteosarcoma cell line used in this work. The authors acknowledge support from CNPq, FAPEMIG and PPGEM. One of the authors acknowledges support from the European Research Council under ERC Grant Agreement No. 267464-SPDMETALS (TGL). 


\section{References:}

1. Hanzi AC, Gerber I, Schinhammer M, Loffler JF, Uggowitzer PJ (2010) On the in vitro and in vivo degradation performance and biological response of new biodegradable $\mathrm{Mg}-\mathrm{Y}$ Zn alloys. Acta Biomaterialia 6:1824-1833

2. Witte F, Hort N, Vogt C, Cohen S, Kainer KU, Willumeit R, Feyerabend F (2008)

Degradable biomaterials based on magnesium corrosion. Current Opinion in Solid State and Materials Science 12:63-72

3. Witte F, Kaese V, Haferkamp H, Switzer E, Meyer-Lindenberg A, Wirth CJ, Windhagen $\mathrm{H}$ (2005) In vivo corrosion of four magnesium alloys and the associated bone response.

Biomaterials 26:3557-3563

4. Zberg B, Ugowitzer PJ, Loffler JF (2009) MgZnCa glasses without clinically observable hydrogen evolution for biodegradable implants. Nature Materials 8 (11):887-891

5. Kirklan NT (2012) Magnesium biomaterials: past, present and future. . Corrosion Engineering, Science and Technology 47:322-328

6. Bahl S, Suwas S, Chatterjee K (2014) The control of crystallographic texture in the use of magnesium as a resorbable biomaterial. RSC Advances 4:55677-55684

7. Xin R, Li B, Li L, Liu Q (2011) Influence of texture on corrosion rate of AZ31 Mg alloy in 3.5 wt.\% NaCl. Materials and Design 32:4548-4552

8. Argade GR, Panigrahi SK, Mishra RS (2012) Effects of grain size on the corrosion resistance of wrought magnesium alloys containing neodymium. Corrosion science 58:145151

9. Saha P, Roy M, Datta MK, Lee B, Kumta PN (2015) Effects of grain refinement on the biocorrosion and in vitro bioactivity of magnesium. Materials Science and Engineering $\mathrm{C}$ 57:294-303

10. Gao JH, Guan SK, Ren ZW, Sun YF, Zhu SJ, Wang B (2011) Homogeneous corrosion of high pressure torsion treated $\mathrm{Mg}-\mathrm{Zn}-\mathrm{Ca}$ alloy in simulated body fluid. Materials Letters 65:691-693

11. Valiev RZ, Islamgaliev RK, Alexandrov IV (2000) Bulk nanostructured materials from severe plastic deformation. Progress in Materials Science 45:103-187

12. Valiev RZ, Langdon TG (2006) Principles of equal-channel angular pressing as a processing toold for grain refinement. Progress in Materials Science 51:881-981

13. Zhilyaev AP, Langdon TG (2008) Using high-pressure torsion for metal processing:

Fundamentals and applications Progress in Materials Science 53 (6):893-979

14. Birbilis N, Ralston KD, Virtanen S, Fraser HL, Davies CHJ (2010) Grain character influences on corrosion of ECAPed pure magnesium. Corrosion Engineering, Science and Technology 45:224-230

15. Figueiredo RB, Poggiali FSJ, Silva CLP, Cetlin PR, Langdon TG (2016) The influence of grain size and strain rate on the mechanical behavior of pure magnesium. Journal of Materials Science 51:3013-3024

16. Gan WM, Zheng MY, Chang H, Wang XJ, Qiao XG, Wu K, Schwebke B, Brokmeier $\mathrm{H}-\mathrm{G}$ (2009) Microstructure and tensile property of the ECAPed pure magnesium. Journal of Alloys and Compounds 470:256-262

17. Yamashita A, Horita Z, Langdon TG (2001) Improving the mechanical properties of magnesium and a magnesium alloy through severe plastic deformation. Materials Science and Engineering A 300:142-147 
18. Huang Y, Figueiredo RB, Baudin T, Brisset F, Langdon TG (2012) Evolution of Strength and Homogeneity in a Magnesium AZ31 Alloy Processed by High-Pressure Torsion at Different Temperatures. Advanced Engineering Materials 14 (11):1018-1026 19. Zhilyaev AP, Kim B-K, Nurislamova GV, Baró MD, Szpunar JA, Langdon TG (2002) Orientation imaging microscopy of ultrafine-grained nickel. Scripta Materialia 46 (8):575580

20. Zhilyaev AP, Nurislamova GV, Kim B-K, Baró MD, Szpunar JA, Langdon TG (2003) Experimental parameters influencing grain refinement and microstructural evolution during high-pressure torsion. Acta Materialia 51 (3):753-765

21. Wongsa-Ngam J, Kawasaki M, Langdon TG (2013) A comparison of microstructures and mechanical properties in a $\mathrm{Cu}-\mathrm{Zr}$ alloy processed using different $\mathrm{SPD}$ techniques. Journal of Materials Science 48 (13):4653-4660

22. Figueiredo RB, Langdon TG (2008) Record Superplastic Ductility in a Magnesium Alloy Processed by Equal-Channel Angular Pressing. Advanced Engineering Materials 10:37-40

23. Xia K, Wang JT, Wu X, Chen G, Gurvan M (2005) Equal channel angular pressing of magnesium alloy AZ31. Materials Science and Engineering A 410-411:324-327

24. Ge Q, Dellasega D, Demir AG, Vedani M (2013) The processing of ultrafine-grained $\mathrm{Mg}$ tubes for biodegradables stents. Acta Biomaterialia 9:8604-8610

25. Figueiredo RB, Sabbaghianrad S, Giwa A, Greer JR, Langdon TG (2017) Evidence for exceptional low temperature ductility in polycrystalline magnesium processed by severe plastic deformation. Acta Materialia 122:322-331.

26. Song D, Ma A, Jiang J, Lin P, Yang D, Fan J (2010) Corrosion behavior of equalchannel-angular-pressed pure magnesium in $\mathrm{NaCl}$ aqueous solution. Corrosion science 52:481-490

27. Wang H, Estrin Y, Fu H, Song G, Zúberová Z (2007) The Effect of Pre-Processing and Grain Structure on the Bio-Corrosion and Fatigue Resistance of Magnesium Alloy AZ31. Advanced Engineering Materials 9 (11):967-972

28. Alvarez-Lopez M, Pereda MD, del Valle JA, Fernandez-Lorenzo M, Garcia-Alonso MC, Ruano OA, Escudero ML (2010) Corrosion behaviour of AZ31 magnesium alloy with different grain sizes in simulated biological fluids. Acta Biomaterialia 6:1763-1771 29. Ralston KD, Birbilis N, Davies CHJ (2010) Revealing the relationship between grain size and corrosion rate of metals. Scripta Materialia 63:1201-1204

30. Iwahashi Y, Wang J, Horita Z, Nemoto M, Langdon TG (1996) Principle of equalchannel angular pressing for the processing of ultra-fine grained materials. Scripta Materialia 35 (2):143-146

31. Furukawa M, Iwahashi Y, Horita Z, Nemoto M, Langdon TG (1998) The shearing characteristics associated with equal-channel angular pressing. Materials Science and Engineering A 257 (2):328-332

32. Song G, Atrens A, StJohn D (2001) An hydrogen evolution method for the estimation of the corrosion rate of magnesium alloys. Magnesium Technology 2001:255-262 33. Metikoš-Hukovic M, Babic R, Grubac Z, Brinic S (1994) Impedance spectroscopic study of aluminium and Al-alloys in acid solution: inhibitory action of nitrogen containing compounds. Journal of Applied Electrochemistry 24:772-778

34. Farias CA, Lins VFC (2011) Corrosion Resistance of Steels Used in Alcohol and Sugar Industry. Chemical Engineering \& Technology 34 (9):1393-1401 
35. Shi Z, Liu M, Atrens A (2010) Measurement of the corrosion rate of magnesium alloys using Tafel extrapolation. Corrosion science 52:579-588

36. Hermawan H, Dubé D, Mantovani D (2010) Developments in metallic biodegradable stents. Acta Biomaterialia 6:1693-1697

37. Agnew SR, Horton JA, Lillo TM, Brown DW (2004) Enhanced ductility in strongly textured magnesium produced by equal channel angular processing. Scripta Materialia 50:377-381

38. Mukai T, Yamanoi M, Watanabe H, Higashi K (2001) Ductility enhancement in AZ31 magnesium alloy by controlling its grain structure. Scripta Materialia 45:89-94 39. Somekawa H, Mukai T (2015) Hall-Petch Breakdown in Fine-Grained Pure Magnesium at Low Strain Rates. Metallurgical and Materials Transactions 46A:894-902 40. Li J, Xu W, Wu X, Ding H, Xia K (2011) Effects of grain size on compressive behaviour in ultrafine grained pure $\mathrm{Mg}$ processed by equal channel angular pressing at room temperature. Materials Science and Engineering A 528:5993-5998 41. Agha NA, Willumeit-Römer R, Laipple D, Luthringer B, Feyerabend F (2016) The Degradation Interface of Magnesium Based Alloys in Direct Contact with Human Primary Osteoblast Cells. PLoS ONE 11 (6):e0157874

42. Figueiredo RB, Langdon TG (2010) Grain refinement and mechanical behavior of a magnesium alloy processed by ECAP. Journal of Materials Science 45:4827-4836 


\section{Table captions:}

Table 1 - Summary of grain size, $d$, yield stress $\left(\boldsymbol{\sigma}_{\mathbf{y}}\right)$, corrosion potential $\left(\mathbf{E}_{\mathbf{C o r r}}\right)$, corrosion current $\left(\mathbf{I}_{\text {Corr }}\right)$, predicted corrosion rate based on electrochemical testing $\left(\Delta \mathbf{W}_{\mathbf{i}}\right)$ and corrosion rate calculated from the evolution of $\mathrm{H}_{2}\left(\Delta \mathbf{W}_{\mathbf{H}}\right)$ during the initial 6 $\mathrm{h}$ of testing and after $48 \mathrm{~h}$ of exposure in $3.5 \mathrm{wt} . \% \mathrm{NaCl}$ solution.

\section{Figure captions:}

Figura 1 - Microstructures of magnesium with different processing histories.

Figure 2 - Stress vs strain curves determined for materials with different processing histories.

Figure 3 - Cell metabolic activity of SAOS exposed for $24 \mathrm{~h}$ to magnesium with different processing histories (as-cast, rolling, rolling and annealing, rolling and ECAP, and HPT).

Figure 4 - Vital status of SAOS cells exposed to Mg-based materials determined by LIVE/DEAD assay, indicating green fluorescence (viable cells) and red fluorescence (dead cells) images.

Figure 5 - Polarization curves determined in $\mathrm{NaCl}$ solution for magnesium with different processing histories.

Figura 6 - Nyquist curves determined in $\mathrm{NaCl}$ solution for magnesium with different processing histories.

Figure 7 - Mass loss rate determined by the evolution of $\mathrm{H}_{2}$ in $\mathrm{NaCl}$ solution for magnesium with different processing histories.

Figure 8 - Appearance of surface of samples from the as-cast material and the material processed by HPT after immersion in $\mathrm{NaCl}$ solution for different times. 
Table 1 - Summary of grain size, $d$, yield stress $\left(\boldsymbol{\sigma}_{\mathbf{y}}\right)$, corrosion potential $\left(\mathbf{E}_{\text {Corr }}\right)$, corrosion current ( $\left.\mathbf{I}_{\text {Corr }}\right)$, predicted corrosion rate based on electrochemical testing $\left(\Delta \mathbf{W}_{\mathbf{i}}\right)$ and corrosion rate calculated from the evolution of $\mathrm{H}_{2}\left(\Delta \mathbf{W}_{\mathrm{H}}\right)$ during the initial $6 \mathrm{~h}$ of testing and after $48 \mathrm{~h}$ of exposure in $3.5 \mathrm{wt} \%$ $\mathrm{NaCl}$ solution.

\begin{tabular}{|c|c|c|c|c|c|c|c|c|}
\hline Processing & $\underset{(\mu \mathrm{m})}{d}$ & $\begin{array}{c}\sigma_{\mathrm{y}} \\
(\mathrm{MPa})\end{array}$ & $\begin{array}{c}\Delta \mathrm{L} / \mathrm{L}_{0} \\
(\%)\end{array}$ & $\begin{array}{l}E_{\text {Corr }} \\
\text { (V) }\end{array}$ & $\begin{array}{c}I_{\text {Corr }} \\
\left(\mathrm{mA}^{-2} \mathrm{~cm}^{-2}\right)\end{array}$ & $\begin{array}{c}\Delta \mathbf{W}_{\mathrm{i}} \\
\left(\mathrm{mg} \cdot \mathrm{cm}^{-2} \cdot \mathrm{h}^{-1}\right)\end{array}$ & $\begin{array}{c}\Delta W_{H}(6 h) \\
\left(m^{\prime} \cdot c^{-2} \cdot h^{-1}\right)\end{array}$ & $\begin{array}{c}\Delta W_{H}(48 h) \\
\left(m g . c m^{-2} \cdot h^{-1}\right)\end{array}$ \\
\hline As-cast & 480 & 34 & 5 & -1.48 & 0.007 & 0.003 & 0.027 & 0.054 \\
\hline Hot-rolling & 16 & 110 & 5 & -1.61 & 0.350 & 0.159 & 0.050 & - \\
\hline $\begin{array}{l}\text { Hot-rolling + } \\
\text { annealing }\end{array}$ & 24 & 110 & 7 & -1.63 & 0.210 & 0.095 & 0.021 & - \\
\hline $\begin{array}{l}\text { Hot-rolling + } \\
\text { ECAP }\end{array}$ & 3.2 & 140 & 8 & -1.51 & 0.040 & 0.018 & 0.065 & 0.025 \\
\hline HPT & 0.56 & 80 & 130 & -1.49 & 0.008 & 0.004 & 0.055 & 0.019 \\
\hline
\end{tabular}



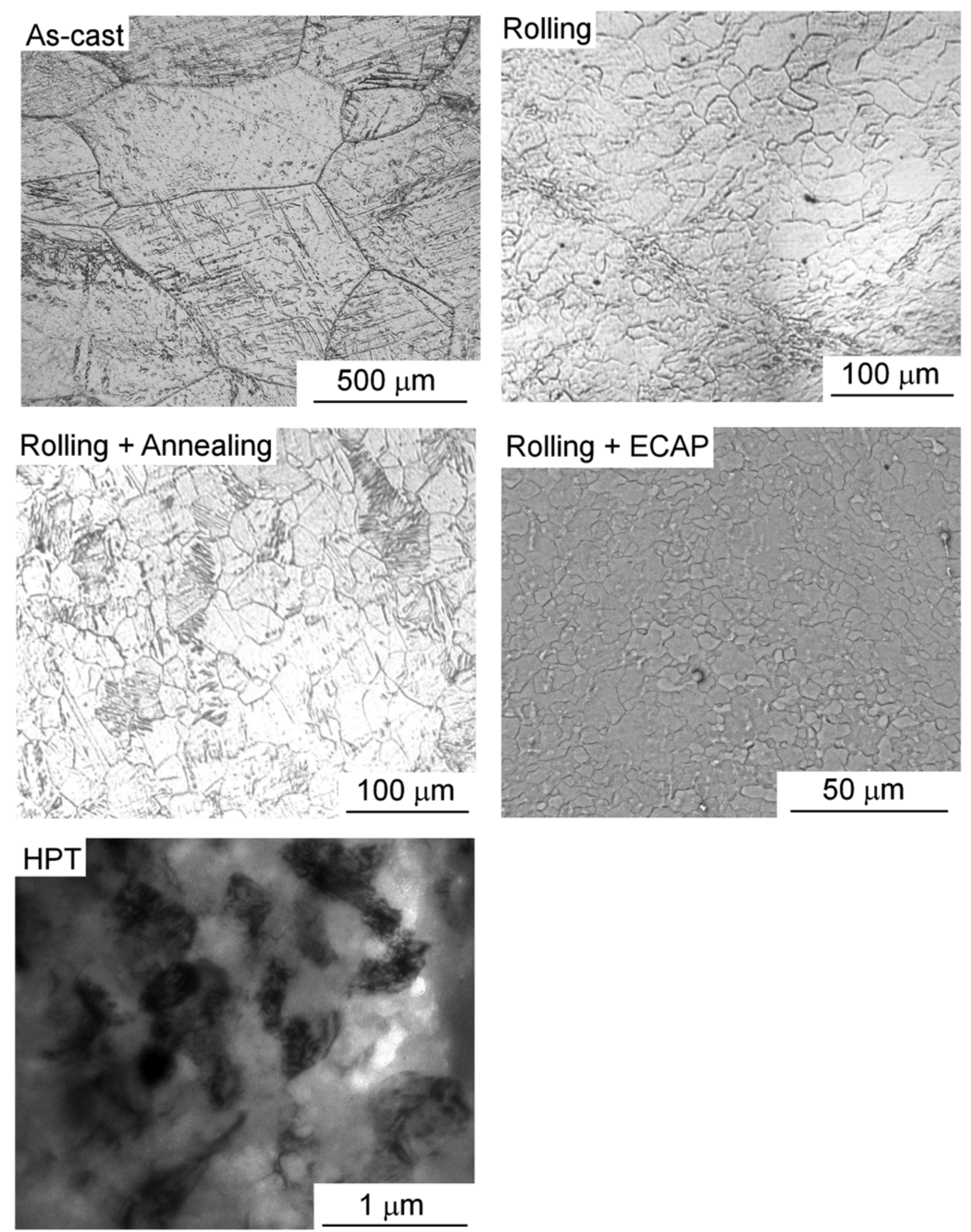

Figura 1 - Microestruture of magnesium with different processing history. 


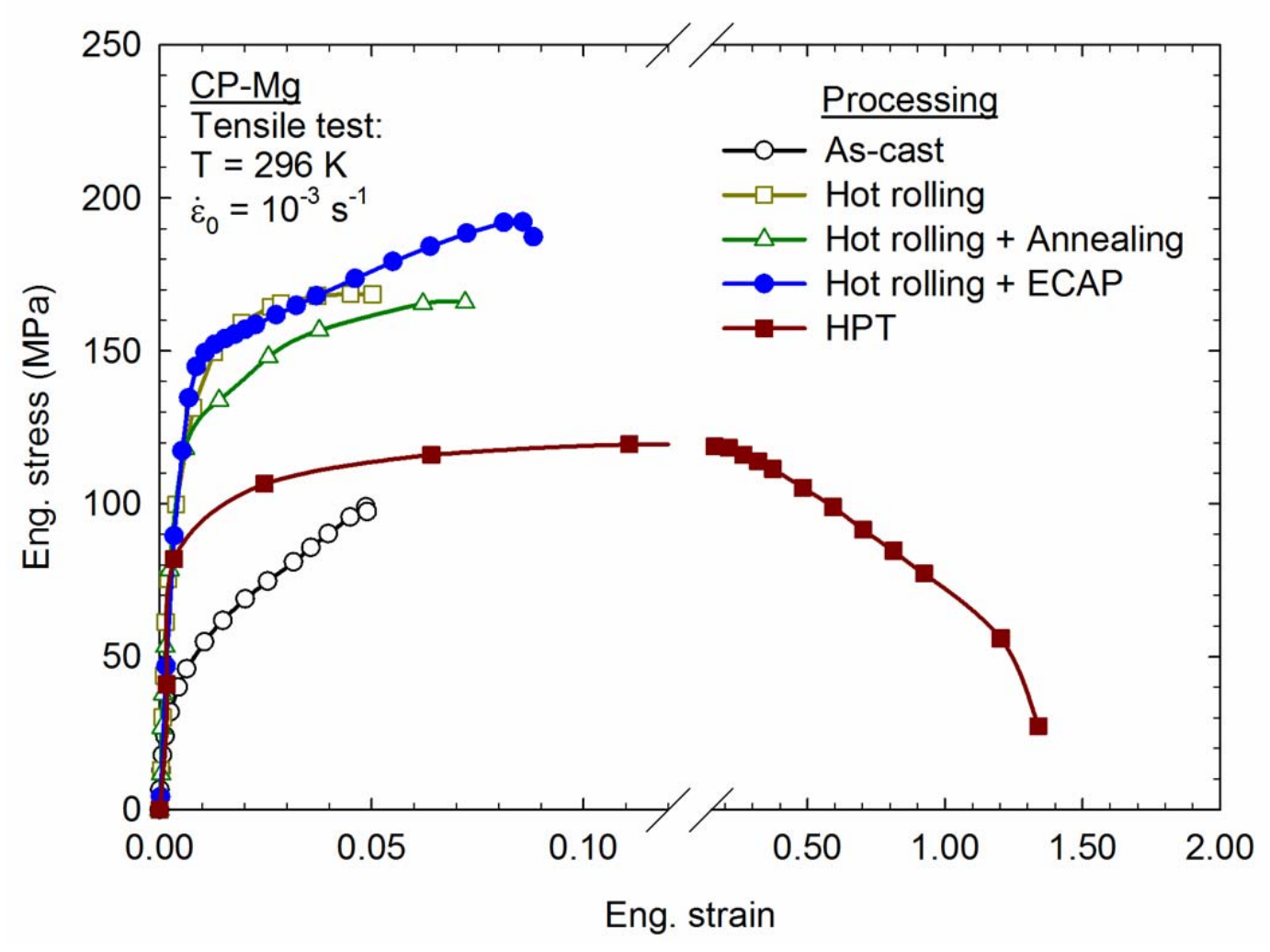

Figure 2 - Stress vs strain curves determined for the material with different processing history. 


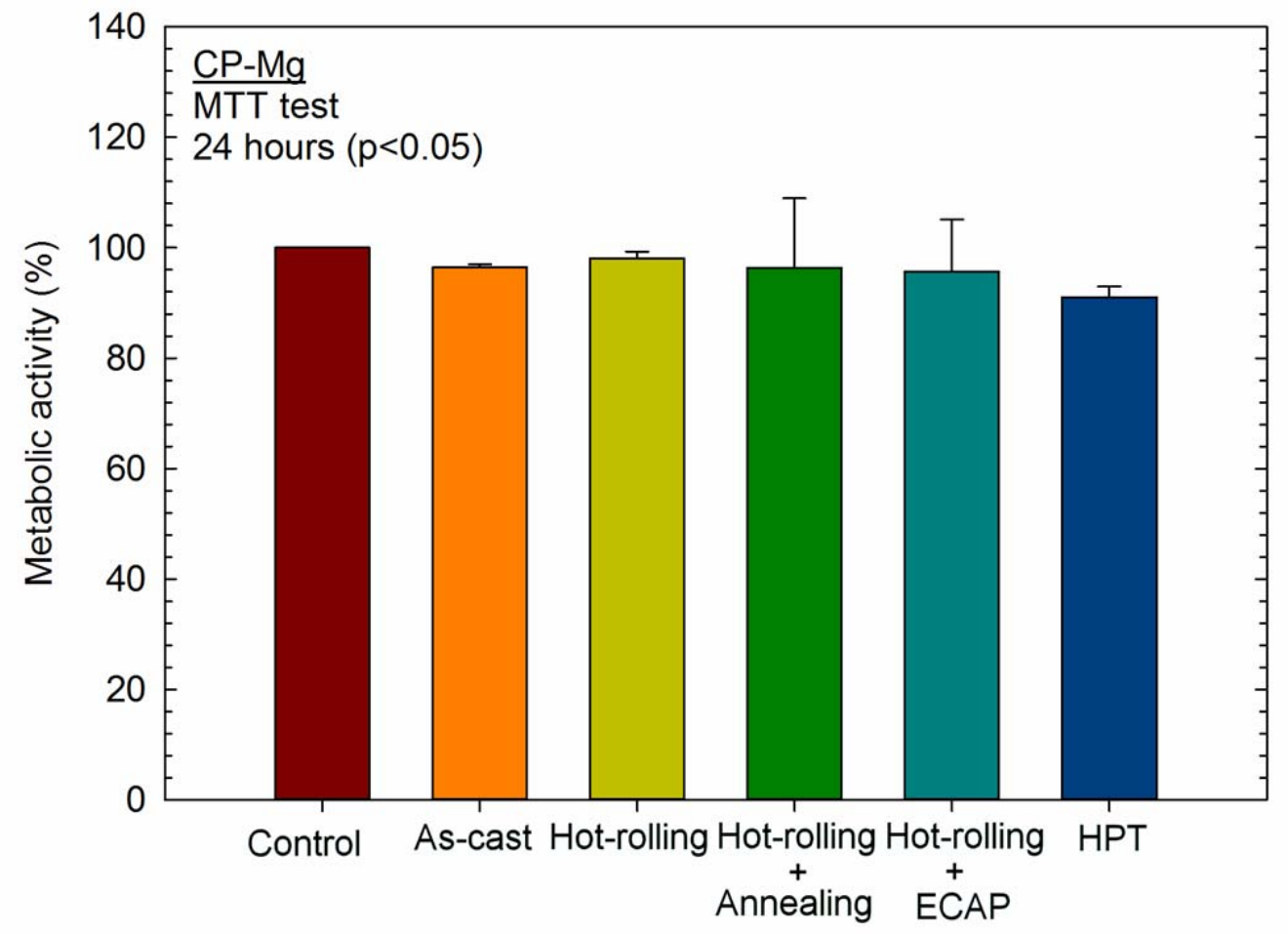

Figure 3 - Cell metabolic activity of SAOS exposed for $24 \mathrm{~h}$ to magnesium with different processing history (as-cast, rolling, rolling and annealing, rolling and ECAP, and HPT). 
CP-Mg

LIVE / DEAD assay

Green fluorescence: viable cells

Red fluorescence: dead cells

\section{$100 \mu \mathrm{m}$}

Negative control

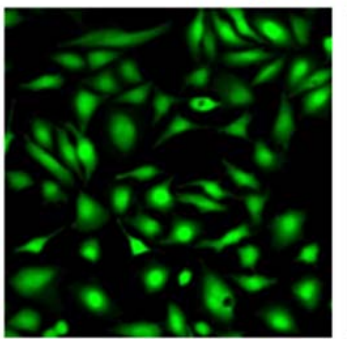

Positive control
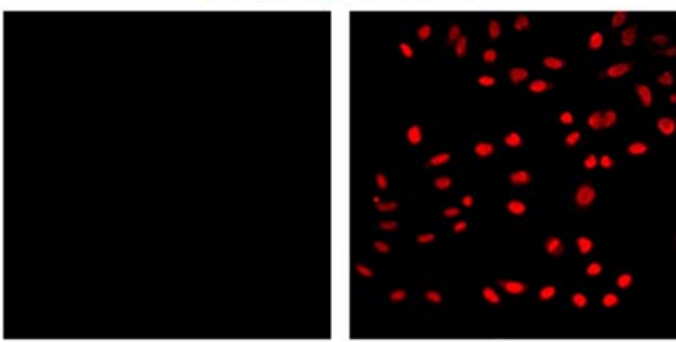

As-cast
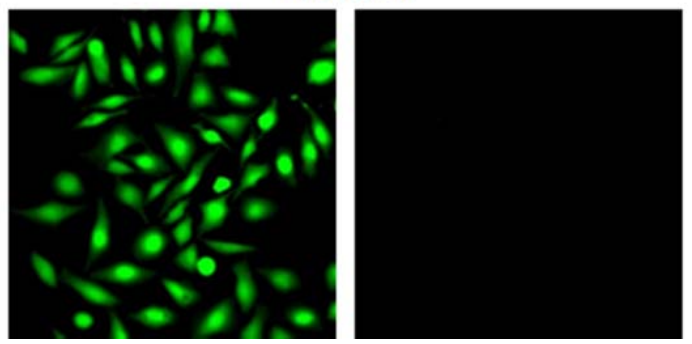

Hot-rolling

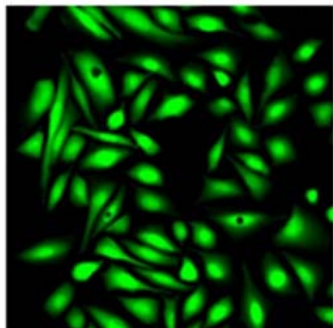

Hot-rolling + Annealing

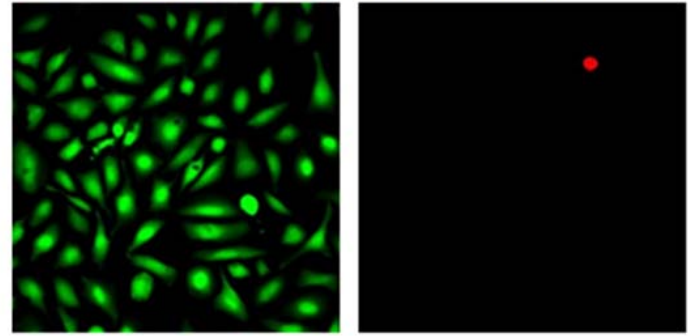

Hot-rolling + ECAP
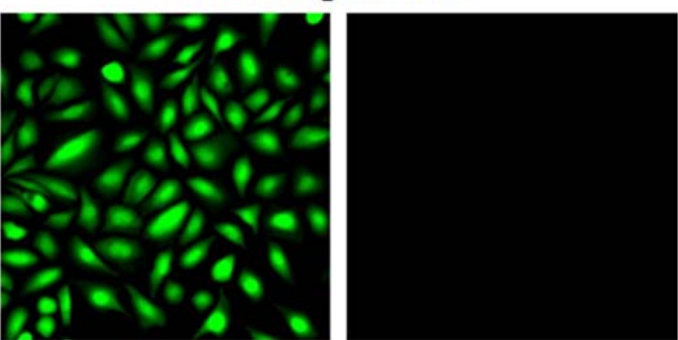

HPT
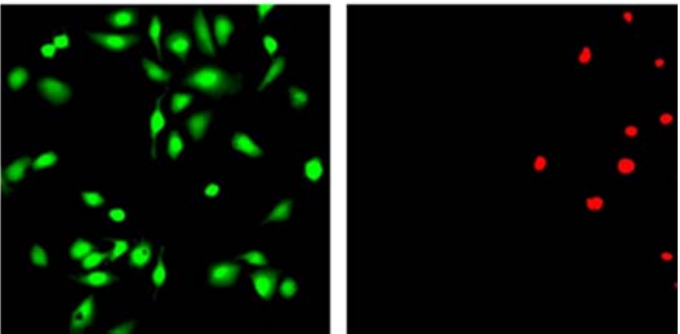

Figure 4 - Vital status of SAOS cells exposed to Mg-based materials determined by LIVE/DEAD assay, indicating green fluorescence (viable cells) and red fluorescence (dead cells) images. 


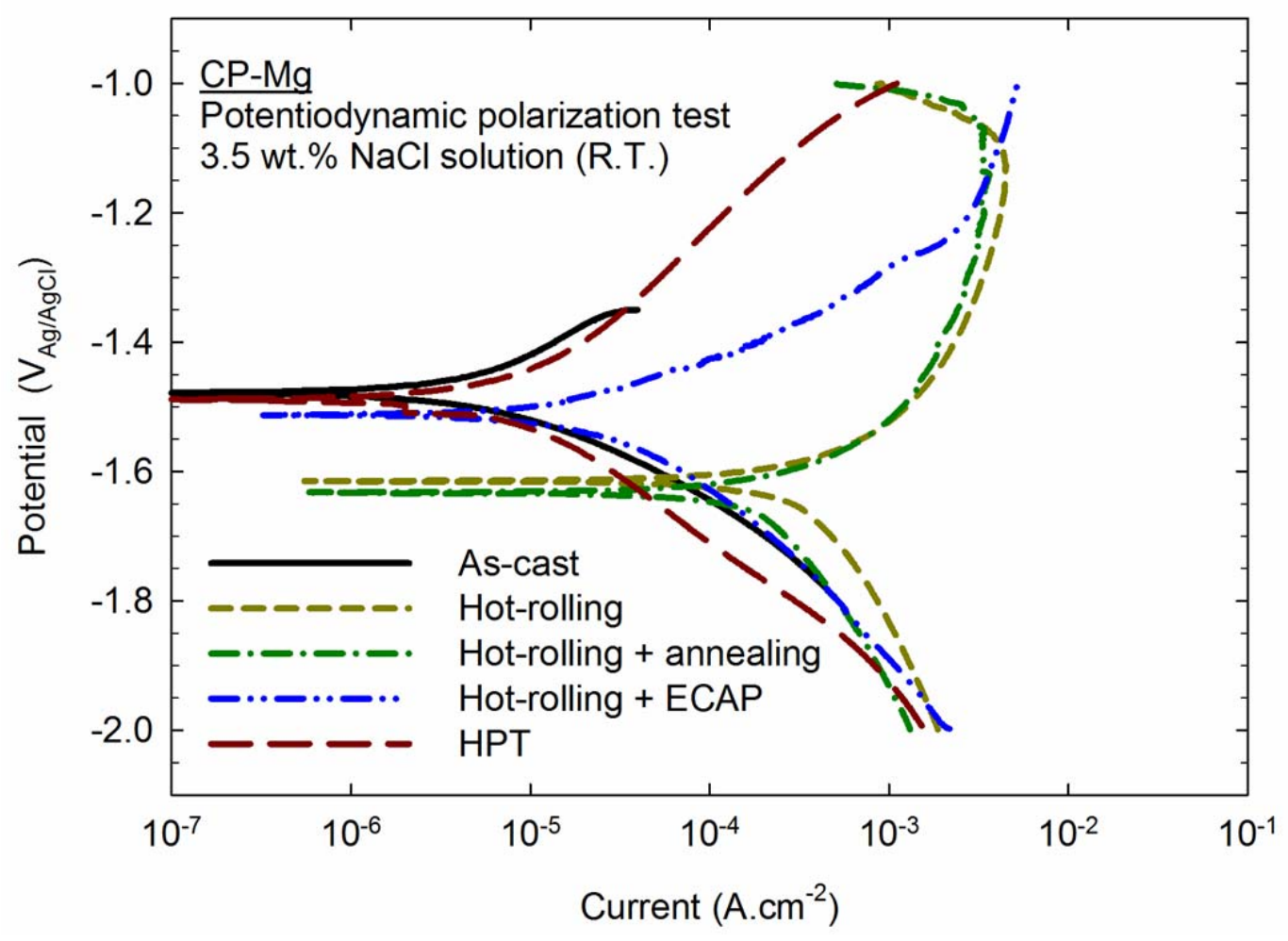

Figure 5 - Polarization curves determined in $\mathrm{NaCl}$ solution for magnesium with different processing history. 


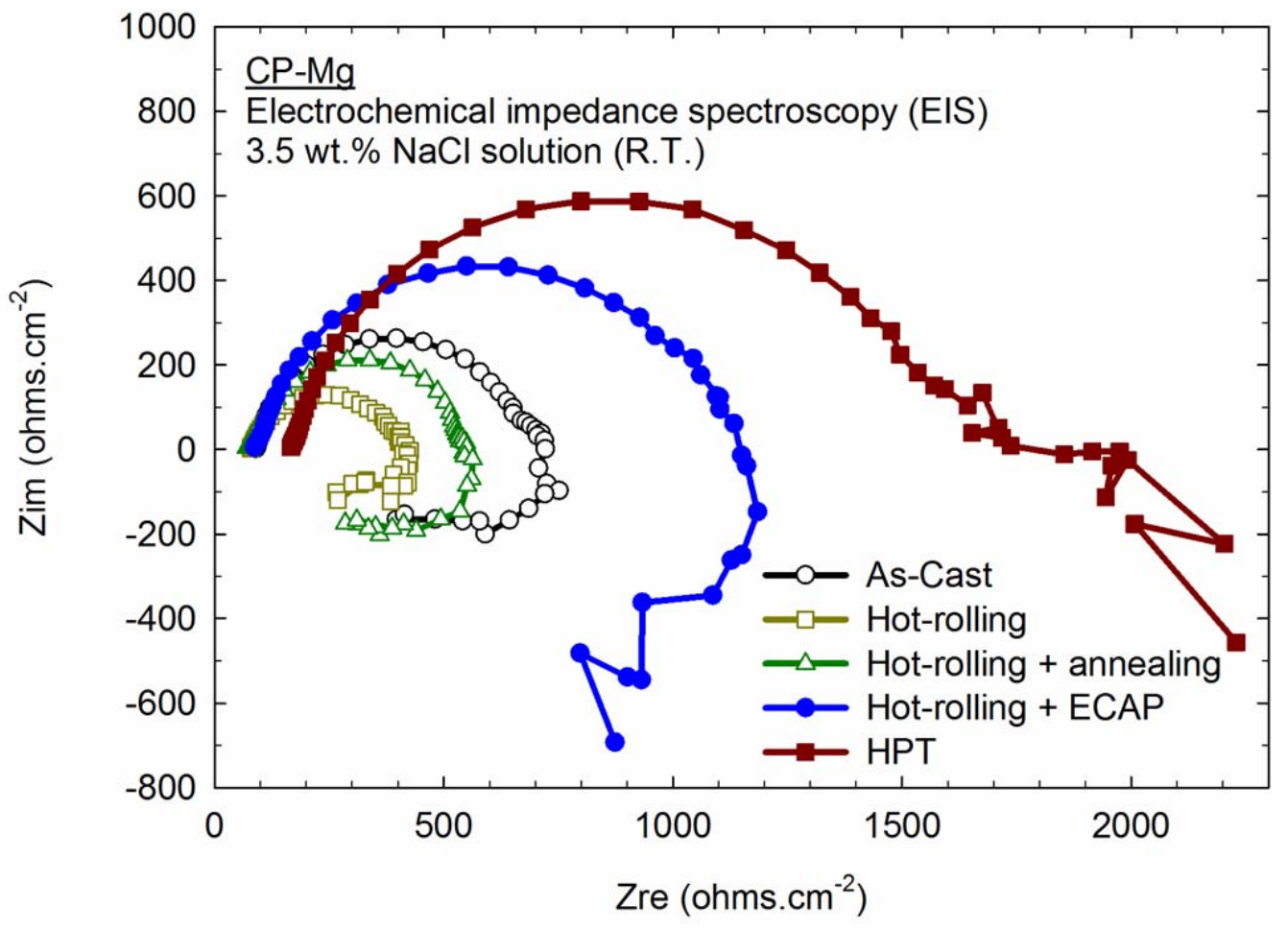

Figura 6 - Nyquist curves determined in $\mathrm{NaCl}$ solution for magnesium with different processing history. 


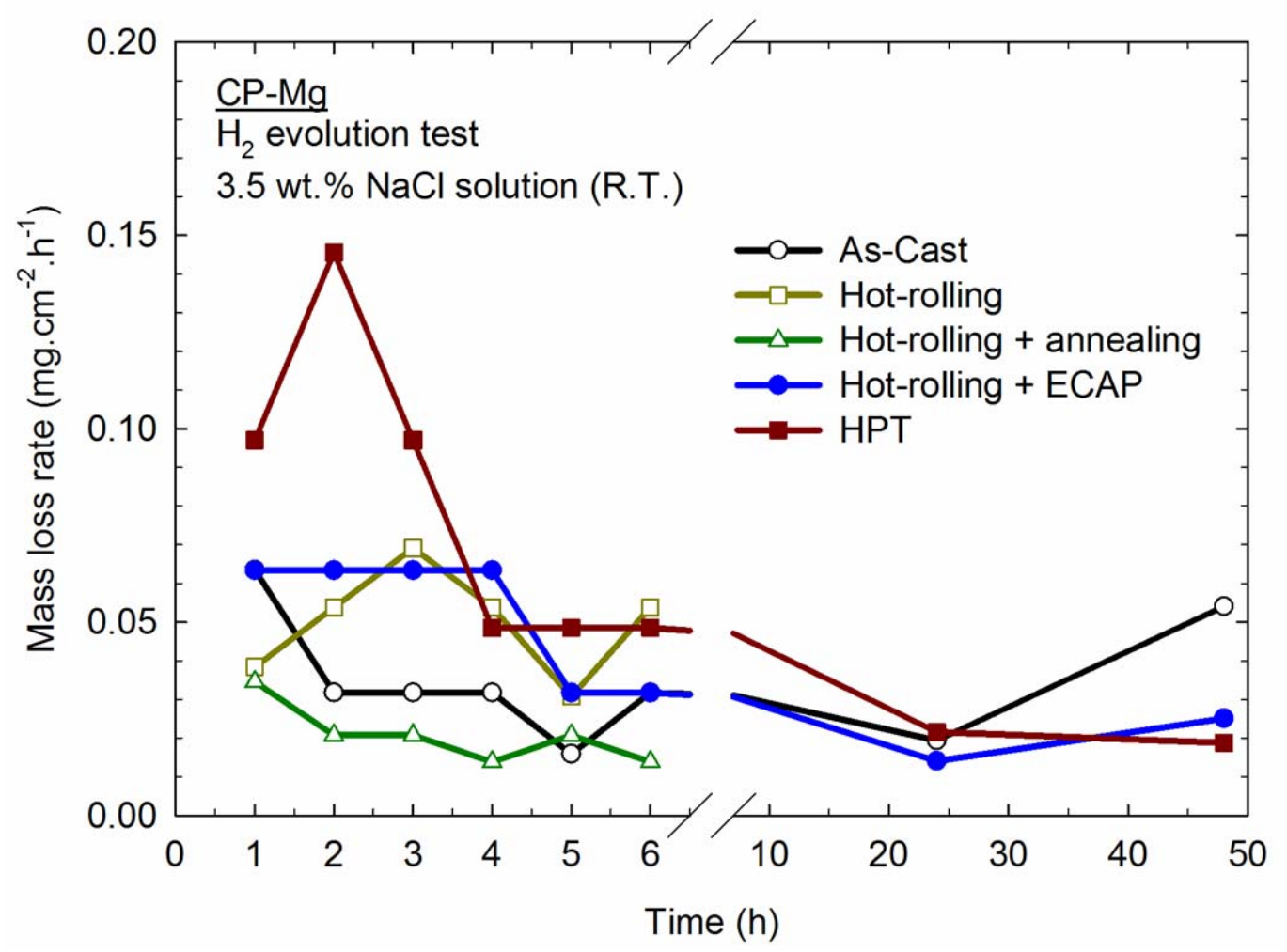

Figure 7 - Mass loss rate determined by the evolution of $\mathrm{H}_{2}$ in $\mathrm{NaCl}$ solution for magnesium with different processing history. 


\section{CP-Mg}

\section{Immersed in 3.5 wt.\% $\mathrm{NaCl}$ solution}

As-cast

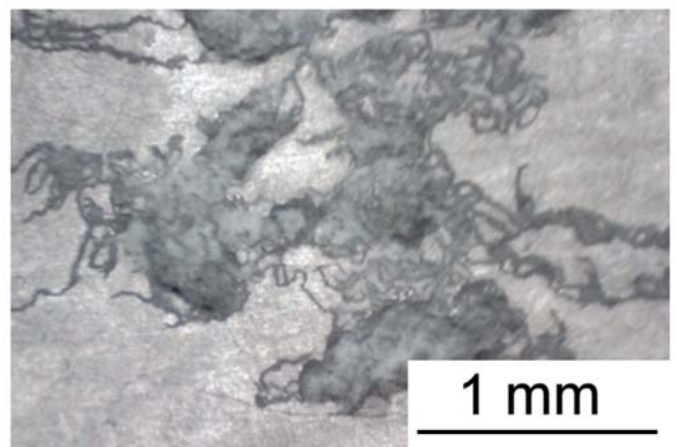

$6 \mathrm{~h}$

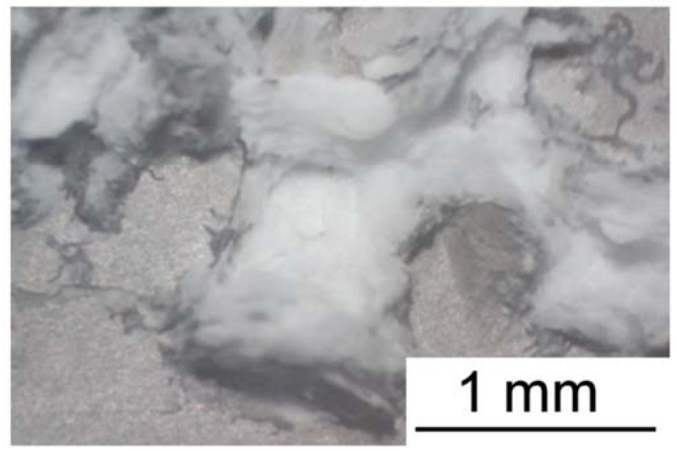

$24 \mathrm{~h}$

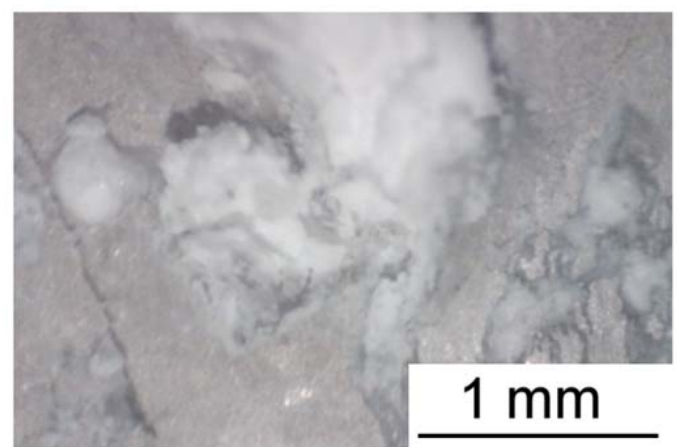

$48 \mathrm{~h}$
HPT: $N=10$

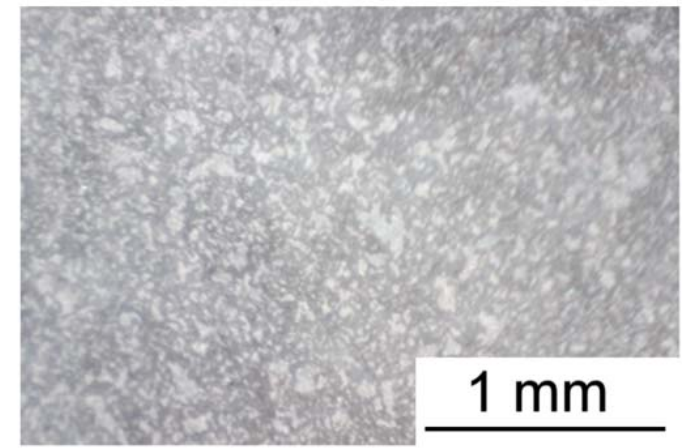

$6 \mathrm{~h}$

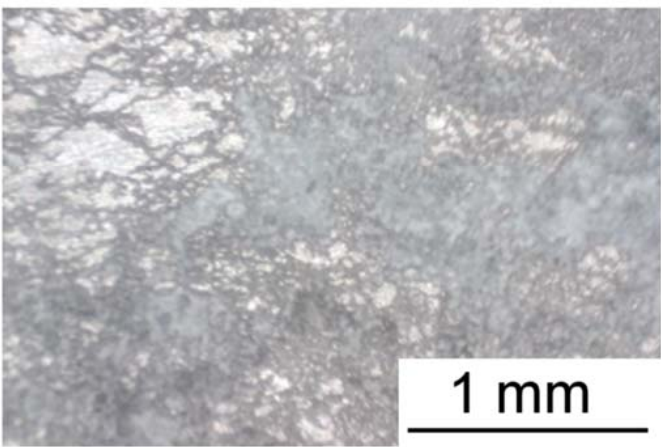

$24 \mathrm{~h}$

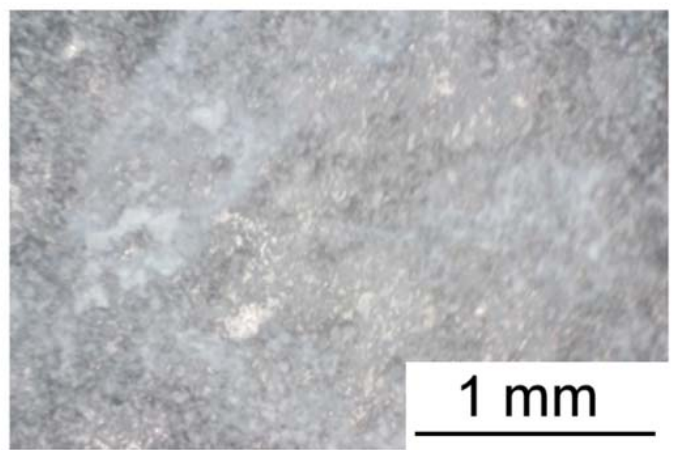

$48 \mathrm{~h}$

Figure 8 - Appearance of surface of samples from the as-cast material and the material processed by HPT after immersion in $\mathrm{NaCl}$ solution for different amount of time. 